\title{
Colonic inflammation accompanies an increase of $\beta$-catenin signaling and Lachnospiraceae/Streptococcaceae bacteria in the hind gut of high-fat diet-fed mice
}

\author{
Huawei Zeng ${ }^{1}$, Suzanne L Ishaq ${ }^{2,3}$, Feng-Qi Zhao ${ }^{2}$, and André-Denis G Wright ${ }^{2,4}$ \\ ${ }^{1}$ United States Department of Agriculture, Agricultural Research Service, Grand Forks Human \\ Nutrition Research Center, Grand Forks, North Dakota 58203; ${ }^{2}$ Department of Animal Science, \\ University of Vermont, Burlington, VT 05405; ${ }^{3}$ Department of Animal and Range Sciences, \\ Montana State University, Bozeman, MT 59717; ${ }^{4}$ School of Animal and Comparative Biomedical \\ Sciences, University of Arizona, Tucson, AZ 85721
}

Running title: Gut inflammation and microbiome The manuscript contains 5252 words, six figures and three tables. Abbreviation used: CRP, C-reactive protein; HF, high-fat; HFD, high-fat diet; IBD, inflammatory bowel disease; IL-6, interleukin 6; iNOS, inducible nitric oxide synthase; LF, low-fat; LFD, low-fat diet; rRNA, ribosomal RNA; TNF- $\alpha$, tumor necrosis factor $\alpha$.

Author disclosures: H Zeng, SL Ishaq, FQ Zhao, and A-D. G Wright, no conflicts of interest.

$\begin{array}{ll}\text { *Corresponding Author: } & \text { Huawei Zeng, Ph.D. } \\ & \text { USDA, ARS, GFHNRC } \\ & \text { P. O. Box 9034 } \\ \text { Grand Forks, ND 58202-9034 } \\ \text { Telephone: 701-795-8465 } \\ \text { Telefax: 701-795-8220 } \\ \text { E-mail: huawei.zeng@ars.usda.gov }\end{array}$

The U.S. Department of Agriculture, Agricultural Research Service, Northern Plains Area, is an equal opportunity/affirmative action employer and all agency services are available without discrimination.

Mention of a trademark or proprietary product does not constitute a guarantee or warranty of the product by the U.S. Department of Agriculture and does not imply its approval to the exclusion of other products that may also be suitable.

This work was supported by the US Department of Agriculture 


\section{Abstract}

2 Consumption of an obesigenic / high-fat (HF) diet is associated with a high colon cancer

3 risk, and may alter the gut microbiota. To test the hypothesis that long-term HF feeding accelerates

4 inflammatory process and changes gut microbiome composition, C57BL/6 mice were fed a HF

5 (45\% energy) or low-fat (LF) (10\% energy) diet for 36 weeks. At the end of the study, body

6 weights in the HF group were $35 \%$ greater than those in the LF group. These changes were

7 associated with dramatic increases in body fat composition, inflammatory cell infiltration,

8 inducible nitric oxide synthase (iNOS) protein concentration and cell proliferation marker (Ki67)

9 in ileum and colon. Similarly, $\beta$-catenin expression was increased in colon (but not ileum).

10 Consistent with gut inflammation phenotype, we also found that plasma leptin, IL6, and tumor

11 necrosis factor- $\alpha$ concentrations were also elevated in mice fed the HF diet, indicative of chronic

12 inflammation. Fecal DNA was extracted and the V1-V3 hypervariable region of the microbial 16S

13 rRNA gene was amplified using primers suitable for 454-pyrosequencing. Compared to the LF

14 group, the HF group had high proportions of bacteria from the family

15 Lachnospiraceae/Streptococcaceae which is known to be involved in the development of

16 metabolic disorders, diabetes and colon cancer. Taken together, our data demonstrate, for the first

17 time, that long-term HF consumption not only increases inflammatory status but also accompanies

18 an increase of colonic $\beta$-catenin signaling and Lachnospiraceae/Streptococcaceae bacteria in the

19 hindgut of C57BL/6 mice.

20 Keywords: colonic inflammation; cancer; high fat; microbiome 


\section{Introduction}

The incidence of inflammatory bowel disease (IBD) is rising in the Western world, as well as in the regions where IBD was previously thought to be uncommon (e.g., China, South Korea) [1]. The precise cause of IBD is unknown. However, the spread of the "Western" diet, high in fat and protein, but low in fruits and vegetables, has been indicated as a promoting factor on the risk of IBD $[2,3]$. High-fat diet (HFD) related obesity has emerged as one of the leading environmental risk factors for IBD and colon cancer development [3-5] as supported by epidemiological studies as well as controlled experimental studies in mice [6-9]. Consumption of a HFD can lead to accumulation of excess body fat that is associated with adipose tissue dysfunction and a chronic state of low-grade inflammation, which is known to promote IBD and tumor development [10,11]. While the pathways that are active in promoting obesity-related gut inflammation remain to be characterized, it is possible that the process may involve the hind gut microbiota, which can affect gut inflammatory status and the extraction of energy from the diet [12-14].

Although there is a growing body of evidence that implicates chronic inflammation as a link between HFD-induced obesity and IBD risk, little is known about the association of intestinal pathohistological status and altered gut microbiota (dysbiosis) in a long-term HF feeding mouse model of obesity. Adipose tissue manifests proinflammatory transformation during both obesity and IBD, and recent data demonstrate that manipulation of the intestinal

42 microbiota alters host immune cell homeostasis and IBD risk $[15,16]$. It is understood that intestinal microbiota play an important role in the pathogenesis of IBD. In addition, IBD patients are well known to have a higher risk of developing colon cancer due to chronic inflammation [17,18]. Therefore, these research areas are now well integrated. The 
46 gastrointestinal tract is poised in a state of equilibrium that permits rapid protective responses

47 against pathogens, but curtails damage by hindering long-lasting vigorous inflammatory

48 processes [19]. The present study addressed this issue and tested the hypothesis that a long-term

49 HF feeding (36 wk) promotes certain gut bacteria and intestinal inflammation.

\section{2. Materials and Methods}

\section{2.1. Animals, diets and treatment}

54 This study was approved by the Animal Care and Use Committee of the Grand Forks

55 Human Nutrition Research Center, and animals were maintained in accordance with NIH

56 guidelines for the care and use of laboratory animals. Male C57BL/6 mice, 5 wk old, were

57 obtained from Charles River Laboratories. Mice were individually housed in Plexiglas ${ }^{\mathrm{TM}}$

58 ventilated cages within a pathogen-free facility that maintained a 12-h light/dark cycle. Mice

59 were given free access to food and deionized water, and were allowed to acclimate in the facility

60 for 2 days before being randomly assigned to two dietary treatment groups $(\mathrm{n}=12$ each). The

61 feeding experiment was conducted for $36 \mathrm{wk}$, and treatments consisted of a LF purified diet (10\%

62 calories from fat, D12450B, Research Diets) or a HF diet (45\% calories from fat, D12451,

63 Research Diets) (Table 1A, B) [20]. Body weight was recorded weekly, and body composition

64 was measured (by MRI scanning, EchoMRI, Houston, TX,) at 9 wk intervals. At the

65 termination of the experiment, mice were feed-deprived for $6 \mathrm{~h}$ and then euthanized with a

66 mixture of ketamine and xylazine. Plasma samples were collected and stored at $-80^{\circ} \mathrm{C}$ for

67 analyses of leptin, interleukin 6 (IL6), tumor necrosis factor-alpha (TNF $\alpha$ ), and C-reactive 
5

68 protein (CRP).

70 2.2. Ileum and colon histology, and iNOS, Ki67 and $\beta$-catenin immunohistochemistry

$71 \quad$ Ileum and colon segments were fixed in $10 \%$ neutral buffered formalin and embedded in

72 paraffin. Five $\mu \mathrm{m}$ sections were mounted on slides and stained with hematoxylin and eosin

73 (H\&E). The iNOS, Ki67 and $\beta$-catenin expressions were assessed using an

74 immunohistochemistry detection kit (Abcam Inc.). Rabbit polyclonal iNOS, Ki67 and

$75 \beta$-catenin antibodies (Abcam Inc.) were diluted 1:100. Each ileum or colon section was scored 76 for the area of infiltration of inflammatory cells, iNOS, Ki67, $\beta$-catenin expression, and their

77 respective total section area $\left(\mathrm{mm}^{2}\right)$ using a standardized determination of morphology $[21,22]$.

78 The target areas were captured by Leica MZ6 stereomicroscope and Leica DFC420 C digital

79 camera, and Image Pro Plus Version 6.2 software (North Central Instruments) was used for

80 quantification of digitized images.

82 2.3. Plasma leptin, IL6, TNF $\alpha$ and CRP

83 The leptin, IL6 and TNF $\alpha$ concentrations were measured in plasma using ELISA kits

84 (R\&D Systems, Inc.). Plasma CRP was assessed by using the CRP (Mouse) assay kit (ANPCO 85 Diagnostics, Salem, NH).

87 2.4. Detection and quantitation of bacterial composition in fecal samples and $16 \mathrm{~S}$ sequencing 88 Fecal pellets were collected from each mouse at wk 18 and wk 36 (two time points) and 89 stored at $-80{ }^{\circ} \mathrm{C}$. DNA was extracted from mouse fecal samples ( 0.1 grams $)$ using the repeated 
90 bead-beating method [23] and the QIAamp DNA stool Mini Kit (Qiagen, Maryland), and DNA 91 was quantified using a NanoDrop 2000C Spectrophotometer (Thermo Scientific, California).

92 The V1 to V3 region of the bacterial 16S rRNA gene was amplified with universal bacteria 93 primers (IDT, California): 27F [24], (5'-AGAGTTTGATCCTGGCTCAG -3') and 519R [25], 94 (5'-GWATTACCGCGGCKGCTG-3'). PCR procedure was taken as follows [26] : initial 95 denaturing at $98^{\circ} \mathrm{C}$ for $4 \mathrm{~min}$, then 34 cycles of $98^{\circ} \mathrm{C}$ for $10 \mathrm{~s}, 50^{\circ} \mathrm{C}$ for $30 \mathrm{~s}, 72^{\circ}$ for $2 \mathrm{~min}$, 96 followed by a final extension step of $72^{\circ} \mathrm{C}$ for $10 \mathrm{~min}$. All PCR results were run on a $1 \%$ agarose 97 gel, and bands from each mouse sample were excised from the agarose gel, combined per 98 sample, and purified using the QIAGEN QIAQuick Gel Extraction Kit (QIAGEN, Maryland) 99 according to manufacturer's instructions. The gel-extracted DNA was re-eluted into EB Buffer, 100 and was quantified using the NanoDrop 2000C Spectrophotometer (ThermoScientific, CA) to a 101 minimum required final concentration of $20 \mathrm{ng} / \mu \mathrm{l}$ per $20 \mu 1$ sample. The DNA amplicons were 102 frozen and shipped overnight to Molecular Research, LP (MR DNA) for Roche 454 103 pyrosequencing with Titanium chemistry. Sequences were deposited online in the Sequence 104 Read Archive (SRA) through NCBI (BioProject PRJNA279260).

2.5. Statistical analysis

107 Results are given as mean \pm standard error (SEM). The effects of diet over time on body 108 weight, lean mass and \% fat mass were analyzed using repeated measures analysis of variance 109 (ANOVA), followed by Tukey contrasts comparing diets at each time point. Cytokine and 110 immunohistochemistry variables were analyzed using t-tests for unequal variances. JMP V10.0 111 (SAS Institute, Inc., Cary, NC) was used for all statistical analyses. To analyze the DNA 112 sequencing data and various statistical measures, the open-source computer software program 
113 MOTHUR ver.1.31 [27] was used, following previously described work-flow [26], coupled 114 with JMP V10.0 and analysis of molecular variance (AMOVA). Differences with a p-value < 1150.05 were considered statistically significant.

\section{3. Results}

\subsection{Effects of HF on plasma inflammatory cytokines}

HF feeding did not significantly affect plasma concentration of CRP. However, the concentrations of plasma leptin, TNF $\alpha$, IL-6 in the HF group were 2.0, 0.5 and 1.7 fold greater than those in the LF group at the end of the experiment, respectively (Fig. 2).

3.3. Effects of HF on inflammatory cell infiltration, iNOS, Ki67, and $\beta$-catenin expression in colon and ileum 
At the end of 36-wk feeding period, histological examination of colon sections revealed

135 that the areas of inflammatory cells, iNOS, Ki67 and $\beta$-catenin expression in the HF group were

136 2.6-, 0.5-, 1.1- and 0.3-fold greater than that in the LF group, respectively (Fig. 3). Similarly,

137 ileum histological sections showed that the areas of inflammatory cells, iNOS and Ki67

138 expression in the HF group were 7.0-, 0.7-, 0.7-fold greater than that in the LF group,

139 respectively (Fig. 4), but $\beta$-catenin expression did not differ between the LF and HF groups.

\subsection{Effects of HF on gut microbial diversity and composition}

Bacterial diversity measures such as abundance-based coverage estimators (ACE),

CHAO, Good's Coverage, and Shannon-Weiner index, as well as shared operational taxonomic units (OTUs) and sequences within groups are provided in Table 2. The values of above

diversity indexes from 4 different groups did not differ (Table 2). However, the number of total OTUs in HF group was higher than that of LF group $(\mathrm{P}<0.05)$ (Table 2). When comparing the HF group with the LF group at the end of 36-wk feeding period, 164 OTUs were shared across the two diets, representing 2,181 shared sequences; the HF group had 809 non-shared OTUs, representing 1,056 non-shared sequences, while the LF had 569 non-shared OTUs representing 703 non-shared sequences (Fig. 5).

In the present study, the phyla Bacteroidetes, Deferribacteres, and Firmicutes were the three major bacterial taxa identified in the hindgut of mice in the present study. There was a marked increase of Firmicutes bacteria in the HF group ( $\mathrm{p}<0.05$ ); $72.9 \%$ (at 18 wk) and 59.1\% (at $36 \mathrm{wk}$ ) in total bacteria in the HF group, compared with that of $30.1 \%$ (at $18 \mathrm{wk}$ ) and $27.4 \%$ (at $36 \mathrm{wk}$ ) in total bacteria in the LF group (Fig. 6A), respectively. Consistent with this 
observation, analysis at the family-level showed that the abundance of bacteria belonging to the families Lachnospiraceae and Streptococcaceae (phylum Firmicutes) was increased because of 158 the HF feeding. Lachnospiraceae bacteria represented $31.9 \%$ (at $18 \mathrm{wk}$ ) and $30.8 \%$ (at $36 \mathrm{wk}$ ) 159 of total bacteria in the HF group, compared with that of $14.8 \%$ (at 18 wk) and $11.0 \%$ (at 36 wk) 160 in total bacteria in the LF group (Fig. 6B), respectively; Streptococcaceae bacteria represented

\section{Discussion}

Undoubtedly, a variety of factors contribute to the etiology of IBD and colon cancer. There is compelling evidence to include diets and the composition of the gut microbiota as key risk factors $[3,18,28]$. A high-risk Western-type diet for experimental animal diet needs to include multiple risk factors which include high in fat and sugar but low in fiber, vitamin D and calcium [29]. However, a diet high in fat (e.g., lard from bacon consumption) has long been considered as a risk factor for IBD and colon cancer [29,30]. Therefore, although lard contains certain amount of linoleic acid, the diet in this study is a widely accepted high (lard) fat diet for animal models to address diet-induced obesity issue which is partially related to a Western diet $[31,32]$.

The current study undertook to examine the hypothesis that long-term HF feeding mediates dysbiosis and increases the inflammatory status of the hind gut. In the present study, 
179 we used a diet high in both total fat and n6:n3 fatty acid ratio (Table 1A, B), to produce

180 outcomes similar to those observed in obese humans [33,34], namely, increased adiposity (Fig.

181 1), and production of proinflammatory cytokines (Fig. 2). proliferative, anti-apoptotic activities and the activation of monocytes/macrophages $[35,36]$.

Although leptin regulates food intake, its proinflammatory properties are to exert

TNF- $\alpha$ is secreted in colonocytes and hepatic tissues in response to stimuli from the gut and circulation, respectively [37]. IL-6 is a pleiotropic cytokine that contributes to enhanced T cell survival and apoptosis resistance at the inflamed site [38]. CRP is a sensitive system marker of inflammation, in particular, acute inflammatory events and tissue damage caused by infections [39]. The fact that long-term HF feeding increased plasma concentrations of proinflammatory cytokines, leptin, TNF- $\alpha$, and IL6, but not CRP, suggest that long-term HF feeding induces a low grade chronic inflammation.

Emerging data demonstrate a promoting effect of a HFD on the risk of IBD [2,3], but little is known about the comparative pathobiology of the hindgut (ileum \& colon) and its association with dysbiosis. To determine whether long term HF feeding mediated hindgut inflammation, we examined the ileum and colon with immunohistochemistry analysis. First, in healthy colonic tissues, few immune cells can be found in the mucosa next to the basal membrane of the epithelial layer but, at the inflamed tissue, the immune cells are greatly increased in the lamina propria of intestine and these cells secret proinflammatory cytokines and other related mediators $[40,41]$. In the present study, long-term HF feeding caused an increase of proinflammatory cells in both ileum and colon (Fig. 3, 4), suggesting that ileum and colon were inflamed to a certain degree. Second, the regulation of proinflammatory cytokines 
released by iNOS may contribute to the pathogenesis of the inflammatory process. It is known that iNOS/nitric oxide plays an integral role during intestinal inflammation, and the expression of iNOS was significantly increased in inflamed colon $[42,43]$. However, whether iNOS is induced in the hindgut in HFD mediated obesity mice is still unclear. That we detected an increase of iNOS protein expression in both ileum and colon provided the detailed distribution of iNOS in ileum and colon with HFD induced obese mice. Third, intestinal inflammation is invariably associated with increased epithelial proliferation. In the colon, it is difficult to examine changes in cell proliferation, but using cell proliferation marker Ki67, epithelial proliferation has been suggested to be increased in inflammatory colon $[44,45]$. Therefore, the increase of Ki67 expression in both ileum and colon in HFD group provides further insights into HFD induced inflammatory gut. Lastly, $\beta$-catenin is another key regulator of colonic

212 inflammation [46], and elevated level of $\beta$-catenin expression is linked with IBD and colon cancer [19]. Our data showed that HF feeding increased $\beta$-catenin level in colon but not ileum.

214 This new observation is consistent with the fact that HFD induced obesity is a higher cancer-risk factor in colon than in ileum $[4,47]$.

The other important aspect of gut inflammatory process is the composition of the gut microbiota, which has emerged as an important factor regulating host health and the onset of IBD and colon cancer [48]. Although there are studies on HFD and gut microbiota [49,50], much remains to be determined at lower taxonomic levels (e.g., family, genus) which vary greatly because of diets, feeding time and species of animal hosts. Little is known about the effect of long-term HF consumption on colonic inflammation and microbiota in a mouse model. To gain further insight into pathophysiology, we then characterized the association between the 
223 increase of immune cell infiltration, iNOS, Ki67, $\beta$-catenin in this study and the respective gut microbiota composition.

The HFD increased the statistical diversity of gut bacteria because total OTUs were increased in the HF group, although Shannon diversity was not statistically different between diets (Table 2, and Fig. 5). This suggests that HF group had a higher diversity of sequences but not of taxonomic diversity. In other words, species or strain level diversity was increased in HF group, but the overall genetic distance of the HF group was not significantly elevated. However, certain bacterial abundance did change due to HF feeding. We found that HF feeding/obesity greatly increased the abundance of Firmicutes bacteria (Fig. 6), which is consistent with the previous report [12]. The longer HF feeding (36 wk vs. 18 wk) did not further increase the abundance of Firmicutes bacteria, and body fat percentage also showed a similar pattern. This observation suggests that the relative increase of the abundance of Firmicutes bacteria was closely related to the percentage of body fat mass in this HF feeding model.

Lachnospiraceae bacteria (phylum Firmicutes, class Clostridia) are in the intestinal tract, but relatively rare elsewhere, the relative abundance of these bacteria was increased by early life subtherapeutic antibiotic treatments in an obese mouse model. Furthermore, Lachnospiraceae bacteria have also been linked to obesity [51,52]. In addition, a metagenomic study indicated that the taxonomic family Lachnospiraceae may be associated with type 2 241 diabetes (T2D) in humans and mouse models $[53,54]$. However, the effect of the HF feeding on the relative abundance of Lachnospiraceae has been elusive, and little data on long-term HF 243 consumption exists in mouse models. Our present data clearly showed that HF feeding greatly 244 increased the abundance of Lachnospiraceae, which is positively correlated with the 
observation that HF feeding also increased inflammatory status in this study. The other important finding is that HF feeding also greatly increased the relative abundance of Streptococcaceae, specifically bacteria belonging to the genus Lactococcus (100\% prevalence). This observation suggests new avenues in understanding HF feeding/obesity related IBD and colon cancer because Streptococcaceae has been associated with metabolic syndrome and colon cancer [55-57].

The present study is one of the first comprehensive reports in which we simultaneously addressed the impact of HFD on IBD, colon cancer risk, and microbiota in a long-term HF feeding animal experiment. Collectively, these results demonstrate that a long-term HF feeding causes obesity-related inflammatory ileum and colon, and increases $\beta$-catenin (colon cancer risk signaling) expression in colon, which is accompanied by an increase of Lachnospiraceae and Streptococcaceae bacteria in the hindgut of C57BL/6 mice.

\section{Acknowledgements}

We greatly appreciate Kay Keehr and James Lindlauf for the technical support. This work was funded by the US Department of Agriculture, Agricultural Research Service, CRIS project (5450-51000-045-00).

\section{Figure legends}

Figure 1, Effect of HF feeding on (A) body weight gain (g); (B) \% body fat mass; (C) body lean mass $(\mathrm{g})$. Values are means \pm SEM, $\mathrm{n}=12$. Different from LF: $* \mathrm{p}<0.05$. 
Figure 2, Effect of HF feeding on plasma (A) leptin, (B) TNFa, (C) IL6, (D) CRP concentrations. Values are means \pm SEM, $\mathrm{n}=12$. Different from LF: $* \mathrm{p}<0.005$.

Figure 3, Colon: comparing with the total cross-section area of the colon, effect of HF feeding on (A), the area of inflammatory cells in percentage; (B), the area of iNOS protein expression in percentage; (C), the area of Ki67 protein expression in percentage; (D), the area of $\beta$-catenin protein expression in percentage. Values are means \pm SEM, $n=10$ to 11 . Different from LF: $* \mathrm{p}$ $272<0.05, * * \mathrm{p}<0.005$

273 Figure 4, Ileum: comparing with the total cross-section area of the ileum, effect of HF feeding 274 on (A), the area of inflammatory cells in percentage; (B), the area of iNOS protein expression in 275 percentage; (C), the area of Ki67 protein expression in percentage; (D), the area of $\beta$-catenin 276 protein expression in percentage. Values are means \pm SEM, $n=9$ to 11. Different from LF: * $p$ $277<0.05, * * \mathrm{p}<0.005$

278 Figure 5, Venn diagram compares HFD (red) with LFD (blue) at 36 wks in terms of shared and 279 non-shared OTUs and sequences.

280 Figure 6, Effects of HF feeding on the abundance of (A) Firmicutes; (B) Lachnospiraceae; (C) 281 Streptococcaceae / Lactococcus. Values are means \pm SEM, $n=6$ at each time point. Different 282 from LF: $* \mathrm{p}<0.05$. 


\section{References}

[1] Hou JK, El-Serag H, Thirumurthi S. Distribution and manifestations of inflammatory bowel disease in Asians, Hispanics, and African Americans: a systematic review. Am J Gastroenterol 2009;104:2100-9.

[2] Amre DK, D'Souza S, Morgan K, Seidman G, Lambrette P, Grimard G, et al. Imbalances in dietary consumption of fatty acids, vegetables, and fruits are associated with risk for Crohn's disease in children. Am J Gastroenterol 2007;102:2016-25.

[3] Hou JK, Abraham B, El-Serag H. Dietary intake and risk of developing inflammatory bowel disease: a systematic review of the literature. Am J Gastroenterol 2011 Apr;106(4):563-73 doi: 10 1038/ajg 2011 44. 2011.

[4] Zeng H, Lazarova DL. Obesity-related colon cancer: dietary factors and their mechanisms of anticancer action. Clin Exp Pharmacol Physiol 2012;39:161-7.

[5] Calle EE, Kaaks R. Overweight, obesity and cancer: epidemiological evidence and proposed mechanisms. Nat Rev Cancer 2004;4:579-91.

[6] Gunter MJ, Leitzmann MF. Obesity and colorectal cancer: epidemiology, mechanisms and candidate genes. J Nutr Biochem 2006;17:145-56.

[7] Padidar S, Farquharson AJ, Williams LM, Kearney R, Arthur JR, Drew JE. High-fat diet alters gene expression in the liver and colon: links to increased development of aberrant crypt foci. Dig Dis Sci 2012;57:1866-74.

[8] Moon HS, Liu X, Nagel JM, Chamberland JP, Diakopoulos KN, Brinkoetter MT, et al. Salutary effects of adiponectin on colon cancer: in vivo and in vitro studies in mice. Gut 2013;62:561-70.

[9] Mladenova D, Kohonen-Corish MR. Review: Mouse models of inflammatory bowel disease--insights into the mechanisms of inflammation-associated colorectal cancer. In Vivo 2012;26:627-46.

[10] van Kruijsdijk RC, van der Wall E, Visseren FL. Obesity and Cancer: The Role of Dysfunctional Adipose Tissue. Cancer Epidemiol Biomarkers Prev 2009;18:2569-78.

[11] Versini M, Jeandel PY, Rosenthal E, Shoenfeld Y. Obesity in autoimmune diseases: Not a passive bystander. Autoimmun Rev 2014;13:981-1000.

[12] Turnbaugh PJ, Ley RE, Mahowald MA, Magrini V, Mardis ER, Gordon JI. An obesity-associated gut microbiome with increased capacity for energy harvest. Nature 2006;444:1027-31.

[13] Cox AJ, West NP, Cripps AW. Obesity, inflammation, and the gut microbiota. Lancet 
[14] Thorburn AN, Macia L, Mackay CR. Diet, metabolites, and "western-lifestyle" inflammatory diseases. Immunity 2014;40:833-42.

[15] Fink C, Karagiannides I, Bakirtzi K, Pothoulakis C. Adipose tissue and inflammatory bowel disease pathogenesis. Inflamm Bowel Dis 2012;18:1550-7.

[16] Ferreira CM, Vieira AT, Vinolo MA, Oliveira FA, Curi R, Martins FD. The Central Role of the Gut Microbiota in Chronic Inflammatory Diseases. J Immunol Res 2014;2014:689492.

[17] Kanauchi O, Mitsuyama K, Andoh A. The therapeutic impact of manipulating microbiota in inflammatory bowel disease. Curr Pharm Des 2009;15:2074-86.

[18] Tomasello G, Tralongo P, Damiani P, Sinagra E, Di Trapani B, Zeenny MN, et al. Dismicrobism in inflammatory bowel disease and colorectal cancer: Changes in response of colocytes. World J Gastroenterol 2014;20:18121-30.

[19] Keerthivasan S, Aghajani K, Dose M, Molinero L, Khan MW, Venkateswaran V, et al. Beta-Catenin promotes colitis and colon cancer through imprinting of proinflammatory properties in T cells. Sci Transl Med 2014;6:225ra28.

[20] Zeng H, Liu J, Jackson MI, Zhao FQ, Yan L, Combs GFJr. Fatty liver accompanies an increase of Lactobacillus species in the hind gut of C57BL/6 mice fed a high-fat diet. J Nutr 2013;143:627-31.

[21] Panchal SK, Poudyal H, Waanders J, Brown L. Coffee extract attenuates changes in cardiovascular and hepatic structure and function without decreasing obesity in high-carbohydrate, high-fat diet-fed male rats. J Nutr 2012;142:690-7.

[22] McCullough AJ. The clinical features, diagnosis and natural history of nonalcoholic fatty liver disease. Clin Liver Dis 2004;8:521-33.

[23] Yu Z, Morrison M. Improved extraction of PCR-quality community DNA from digesta and fecal samples. Biotechniques 2004;36:808-12.

[24] Lane DJ. 16S/23S rRNA sequencing. In: Stackebrandt E, Goodfellow M (eds) Nucleic acid techniques in bacterial systematics, John Wiley and Sons, New York City, 1991, p. 115-175.

[25] Ovreås L, Forney L, Daae FL, Torsvik V. Distribution of bacterioplankton in meromictic Lake Saelenvannet, as determined by denaturing gradient gel electrophoresis of PCR-amplified gene fragments coding for 16S rRNA. Appl Environ Microbiol 1997;63:3367-73. 
[26] Ishaq SL, Wright AD. High-throughput DNA sequencing of the ruminal bacteria from moose (Alces alces) in Vermont, Alaska, and Norway. Microb Ecol 2014;68:185-95.

[27] Schloss PD, Westcott SL, Ryabin T, Hall JR, Hartmann M, Hollister EB, et al. Introducing mothur: open-source, platform-independent, community-supported software for describing and comparing microbial communities. Appl Environ Microbiol 2009;75:7537-41.

[28] Turnbaugh PJ, Bäckhed F, Fulton L, Gordon JI. Diet-induced obesity is linked to marked but reversible alterations in the mouse distal gut microbiome. Cell Host Microbe 2008;3:213-23.

[29] Newmark HL, Yang K, Kurihara N, Fan K, Augenlicht LH, Lipkin M. Western-style diet-induced colonic tumors and their modulation by calcium and vitamin D in C57Bl/6 mice: a preclinical model for human sporadic colon cancer. Carcinogenesis 2009;30:88-92.

[30] Paik J, Fierce Y, Treuting PM, Brabb T, Maggio-Price L. High-fat diet-induced obesity exacerbates inflammatory bowel disease in genetically susceptible Mdr1a-/- male mice. J Nutr 2013;143:1240-7.

[31] Kimball SR, Ravi S, Gordon BS, Dennis MD, Jefferson LS. Amino Acid-Induced Activation of mTORC1 in Rat Liver Is Attenuated by Short-Term Consumption of a High-Fat Diet. J Nutr 2015;145:2496-502.

[32] Chen YJ, Wallig MA, Jeffery EH. Dietary Broccoli Lessens Development of Fatty Liver and Liver Cancer in Mice Given Diethylnitrosamine and Fed a Western or Control Diet. J Nutr 2016;146:542-50.

[33] Smith BK, Andrews PK, West DB. Macronutrient diet selection in thirteen mouse strains. Am J Physiol Regul Integr Comp Physiol. 2000; 278:R797-805.

[34] Comuzzie AG, Allison DB. The search for human obesity genes. Science 1998; 280:1374-7.

[35] La Cava A. Proinflammatory activities of leptin in non-autoimmune conditions. Inflamm Allergy Drug Targets 2012; 11: 298-302.

[36] Fantuzzi G. Adipose tissue, adipokines, and inflammation. J Allergy Clin Immunol 2005 May;115(5):911-9. 2005.

[37] Prieto-Hontoria PL, Pérez-Matute P, Fernández-Galilea M, Bustos M, Martinez JA, Moreno-Aliaga MJ. Role of obesity-associated dysfunctional adipose tissue in cancer: a molecular nutrition approach. Biochim Biophys Acta 2011; 1807:664-78.

[38] Weigmann B, Lehr HA, Yancopoulos G, Valenzuela D, Murphy A, Stevens S, Schmidt J, 

IL-6-dependent T cell activation in experimental colitis. J Exp Med 2008;205:2099-110.

[39] Pepys MB, Hirschfield GM. C-reactive protein: a critical update. J Clin Invest 2003;111:1805-12.

[40] Nagashima R, Maeda K, Imai Y, Takahashi T. Lamina propria macrophages in the human gastrointestinal mucosa: their distribution, immunohistological phenotype, and function. J Histochem Cytochem 1996;44:721-31.

[41] Rugtveit J, Brandtzaeg P, Halstensen TS, Fausa O, Scott H. Increased macrophage subset in inflammatory bowel disease: apparent recruitment from peripheral blood monocytes. Gut 1994;35:669-74.

[42] Svec J, Musílková J, Bryndová J, Jirásek T, Mandys V, Kment M, Pácha J. Enhanced expression of proproliferative and antiapoptotic genes in ulcerative colitis-associated neoplasia. Inflamm Bowel Dis 2010;16:1127-37.

[43] Hiraku Y, Kawanishi S, Ichinose T, Murata M. The role of iNOS-mediated DNA damage in infection- and asbestos-induced carcinogenesis. Ann N Y Acad Sci 2010;1203:15-22.

[44] MacDonald TT. Epithelial proliferation in response to gastrointestinal inflammation. Ann N Y Acad Sci 1992;664:202-9.

[45] Stromar IK, Jakic-Razumovic J. The value of immunohistochemical determination of topoisomerase II $\alpha$ and $\mathrm{Ki} 67$ as markers of cell proliferation and malignant transformation in colonic mucosa. Appl Immunohistochem Mol Morphol 2014;22:524-9.

[46] Soletti RC, Rodrigues NA, Biasoli D, Luiz RR, de Souza HS, Borges HL. Immunohistochemical analysis of retinoblastoma and $\beta$-catenin as an assistant tool in the differential diagnosis between Crohn's disease and ulcerative colitis. PLoS One 2013;8:e70786.

[47] Bernstein H, Bernstein C, Payne CM, Dvorakova K, Garewal H. Bile acids as carcinogens in human gastrointestinal cancers. Mutat Res 2005;589:47-65.

[48] Hörmannsperger G, Clavel T, Haller D. Gut matters: microbe-host interactions in allergic diseases. J Allergy Clin Immunol 2012;129:1452-9.

[49] Murtaza N, Baboota RK, Jagtap S, Singh DP, Khare P, Sarma SM, et al. Finger millet bran supplementation alleviates obesity-induced oxidative stress, inflammation and gut microbial derangements in high-fat diet-fed mice. Br J Nutr 2014;112:1447-58.

[50] Daniel H, Moghaddas Gholami A, Berry D, Desmarchelier C, Hahne H, et al. High-fat diet alters gut microbiota physiology in mice. ISME J 2014;8(2):295-308. 
[51] Cho I, Yamanishi S, Cox L, Methé BA, Zavadil J, Li K, et al. Antibiotics in early life alter the murine colonic microbiome and adiposity. Nature 2012;488:621-6.

[52] Meehan CJ, Beiko RG. A phylogenomic view of ecological specialization in the Lachnospiraceae, a family of digestive tract-associated bacteria. Genome Biol Evol 2014;6:703-13.

[53] Qin J, Li Y, Cai Z, Li S, Zhu J, Zhang F, et al. A metagenome-wide association study of gut microbiota in type 2 diabetes. Nature 2012;490:55-60.

[54] Kameyama K, Itoh K. Intestinal Colonization by a Lachnospiraceae Bacterium Contributes to the Development of Diabetes in Obese Mice. Microbes Environ 2014; 29:427-30.

[55] Qiao Y, Sun J, Xie Z, Shi Y, Le G. Propensity to high-fat diet-induced obesity in mice is associated with the indigenous opportunistic bacteria on the interior of Peyer's patches. $J$ Clin Biochem Nutr 2014;55:120-8.

[56] Aran A, Lin L, Finn LA, Weiner K, Peppard P, Young T, Mignot E. Post-streptococcal antibodies are associated with metabolic syndrome in a population-based cohort. PLoS One 2011;6(9):e25017.

[57] Abdulamir AS, Hafidh RR, Abu Bakar F. The association of Streptococcus bovis/gallolyticus with colorectal tumors: the nature and the underlying mechanisms of its etiological role. J Exp Clin Cancer Res 2011;30:11. 
Table 1A Composition of experimental diets

\begin{tabular}{|c|c|c|c|c|}
\hline \multirow{2}{*}{$\begin{array}{l}\text { Ingredient } \\
\text { Casein, lactic }\end{array}$} & \multicolumn{2}{|c|}{$\begin{array}{l}\text { Low-Fat (LF), } \\
\text { gm } \\
\text { kcal }\end{array}$} & \multicolumn{2}{|c|}{$\begin{array}{l}\text { High-Fat }(\mathrm{HF}) \text {, } \\
\text { gm } \\
\text { kcal }\end{array}$} \\
\hline & 200 & 800 & 200 & 800 \\
\hline L-Cystine & 3 & 12 & 3 & 12 \\
\hline Corn Starch & 315 & 1260 & 72.8 & 291 \\
\hline MaltoDextrin & 35 & 140 & 100 & 400 \\
\hline Sucrose & 350 & 1400 & 172.8 & 691 \\
\hline Cellulose, BW200 & 50 & 0 & 50 & 0 \\
\hline Soybean Oil & 25 & 225 & 25 & 225 \\
\hline Lard & 20 & 180 & 177.5 & 1598 \\
\hline Trace Element $\mathrm{Mix}^{\mathrm{b}}$ & 10 & 0 & 10 & 0 \\
\hline Dicalcium phosphate & 13 & 0 & 13 & 0 \\
\hline Calcium Carbonate & 5.5 & 0 & 5.5 & 0 \\
\hline Potassium Citrate, $1 \mathrm{H}_{2} \mathrm{O}$ & 16.5 & 0 & 16.5 & 0 \\
\hline Vitamin Mix $^{c}$ & 10 & 40 & 10 & 40 \\
\hline Choline Bitartrate & 2 & 0 & 2 & 0 \\
\hline Total & 1055.05 & 4057 & 858.15 & 4057 \\
\hline \multicolumn{5}{|c|}{ Calculated content } \\
\hline Total energy, kcal/kg & 3700 & & 4600 & \\
\hline Total fat, $\mathrm{g} / \mathrm{kg}$ & 42.7 & & 235.3 & \\
\hline Fat calories, $\%$ & 10 & & 45 & \\
\hline n6:n3 fatty acid ratio & 8.3 & & 12.5 & \\
\hline
\end{tabular}

${ }^{a}$ Research Diets, Inc., New Brunswick, NJ.

${ }^{\mathrm{b}}$ Amounts per $10 \mathrm{~g}$ of premix: $0.5 \mathrm{~g} \mathrm{Mg}, 0.3 \mathrm{~g} \mathrm{~S}, 1.0 \mathrm{~g} \mathrm{Na}, 1.6 \mathrm{~g} \mathrm{Cl}, 6.0 \mathrm{mg} \mathrm{Cu}, 0.2 \mathrm{mg} \mathrm{I}, 45.0 \mathrm{mg} \mathrm{Fe,} \mathrm{59mg} \mathrm{Mn,} 0.2$ mg Se and $29 \mathrm{mg} \mathrm{Zn}$.

${ }^{\mathrm{C}}$ Amount per $10 \mathrm{~g}$ of premix:: $4000 \mathrm{IU}$ vitamin A palmitate, $1000 \mathrm{IU}$ cholecalciferol, 50 IU vitamin E acetate, 0.5 $\mathrm{mg}$ menadione sodium bisulfate, $0.2 \mathrm{mg}$ biotin, $10 \mathrm{mg}$ cyanocobalamin, $2 \mathrm{mg}$ folic acid, $30 \mathrm{mg}$ nicotinic acid, $16 \mathrm{mg}$ calcium pantothenate, $7 \mathrm{mg}$ pyridoxine-HCL, $6 \mathrm{mg}$ riboflavin, $6 \mathrm{mg}$ thiamin $\mathrm{HCl}$. 
Table 1B Composition of fats in experimental diet

\begin{tabular}{|c|c|c|}
\hline Ingredient (gm) & Low-Fat (LF), & High-Fat (HF), \\
\hline Lard & 20 & 177.5 \\
\hline Soybean Oil & 25 & 25 \\
\hline Total & 45 & 202.5 \\
\hline 10:0, Capric & 0.0 & 0.1 \\
\hline 12:0, Lauric & 0.0 & 0.2 \\
\hline 14:0, Myristic & 0.2 & 2.0 \\
\hline 14:1n-7, Myristoleic & 0 & 0 \\
\hline 16:0, Palmitic & 6.5 & 36.9 \\
\hline 16:1n-7, Palmitoleic & 0.3 & 2.4 \\
\hline 18:0, Stearic & 3.1 & 19.8 \\
\hline 18:1n-9, Oleic & 12.6 & 64.4 \\
\hline 18:2n-6, Linoleic & 18.3 & 56.7 \\
\hline 18:3n-3,alpha- Linolenic & 2.2 & 4.3 \\
\hline 18:4n-3, Stearidonic & 0 & 0 \\
\hline 20, Arachidic & 0.0 & 0.3 \\
\hline 20:1n-9 Eicosenoic & 0.1 & 1.1 \\
\hline 20:2 n-6 Eicosadienoic & 0.2 & 1.4 \\
\hline 20:3n-3 Eicosatrienoic & 0.0 & 0.2 \\
\hline 20:4n-6, Arachidonic & 0.1 & 0.5 \\
\hline 22:5n-3, Docosapentaenoic & 0.0 & 0.2 \\
\hline 22:6n-3, Docosahexaenoic & 0 & 0 \\
\hline Total & 43.7 & 191.3 \\
\hline
\end{tabular}


Table 2 Mean statistical measures of bacterial diversity, per group

\begin{tabular}{|l|c|c|c|c|}
\hline & LFD & LFD & HFD & HFD \\
\cline { 2 - 5 } & 18 weeks & 36 weeks & 18 weeks & 36 weeks \\
\hline Total Seq & $13685(2731)$ & $10373(2343)$ & $10021(3165)$ & $7108(1225)$ \\
\hline Total OTUs* & $152(5)$ & $153(4.23)$ & $269(4.94)$ & $205(2.97)$ \\
\hline ACE & $1519(55)$ & $1442(296)$ & $1442(169)$ & $1318(117)$ \\
\hline CHAO & $582(58)$ & $574(97.4)$ & $572(55)$ & $553(22.6)$ \\
\hline Good's Coverage & $0.48(0.026)$ & $0.5(0.03)$ & $0.49(0.026)$ & $0.48(0.016)$ \\
\hline Shannon-Weiner & $4.18(0.12)$ & $4.25(0.08)$ & $4.19(0.126)$ & $4.26(0.074)$ \\
\hline
\end{tabular}

* Number of total OTUs in HF group was higher than that of LF group $(\mathrm{p}<0.05)$. Standard error mean (SEM) is given in parentheses. Total sequences are those which passed quality assurance steps. 
A

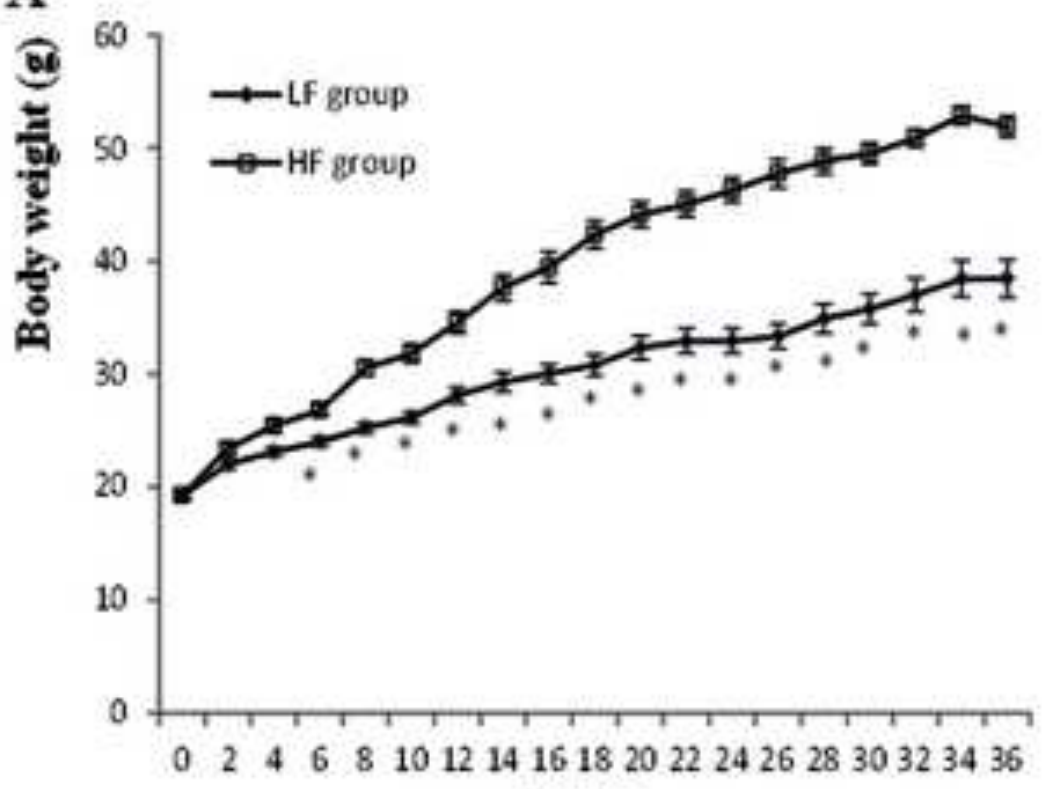

B

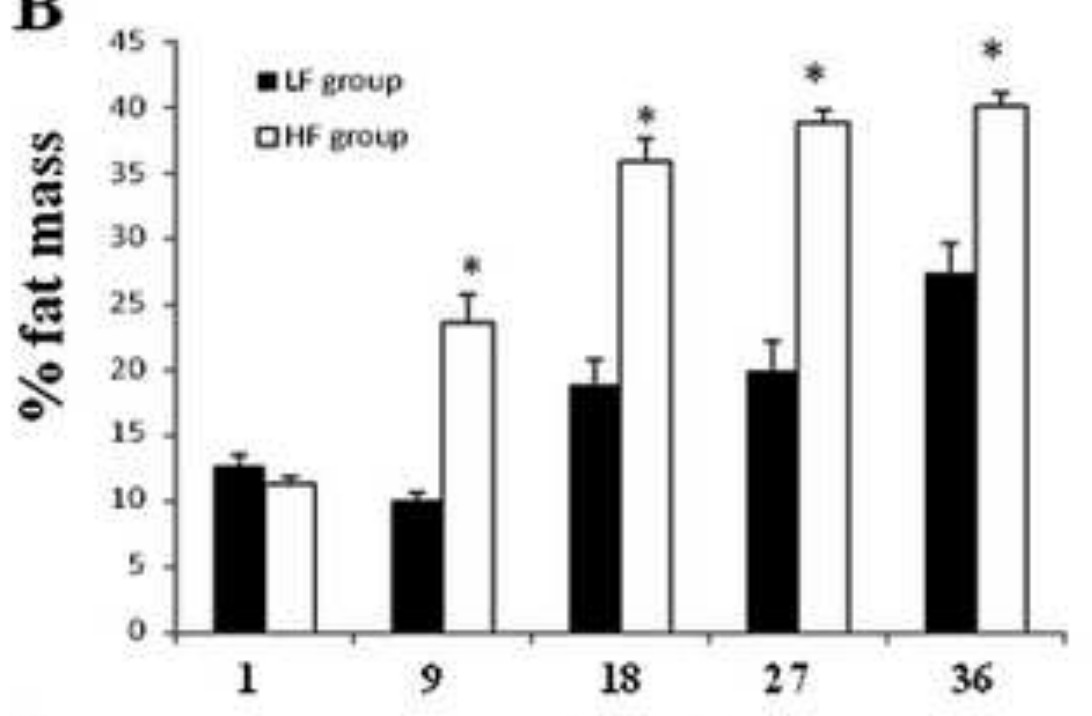

C

Weeks

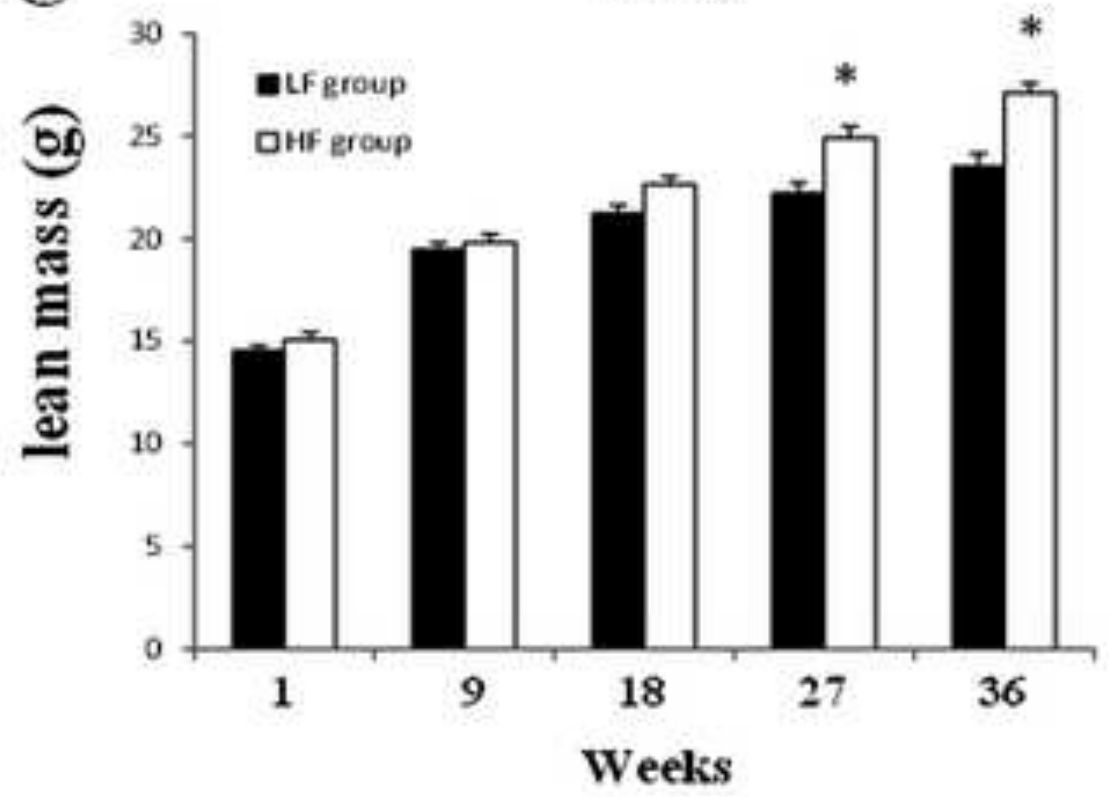


A

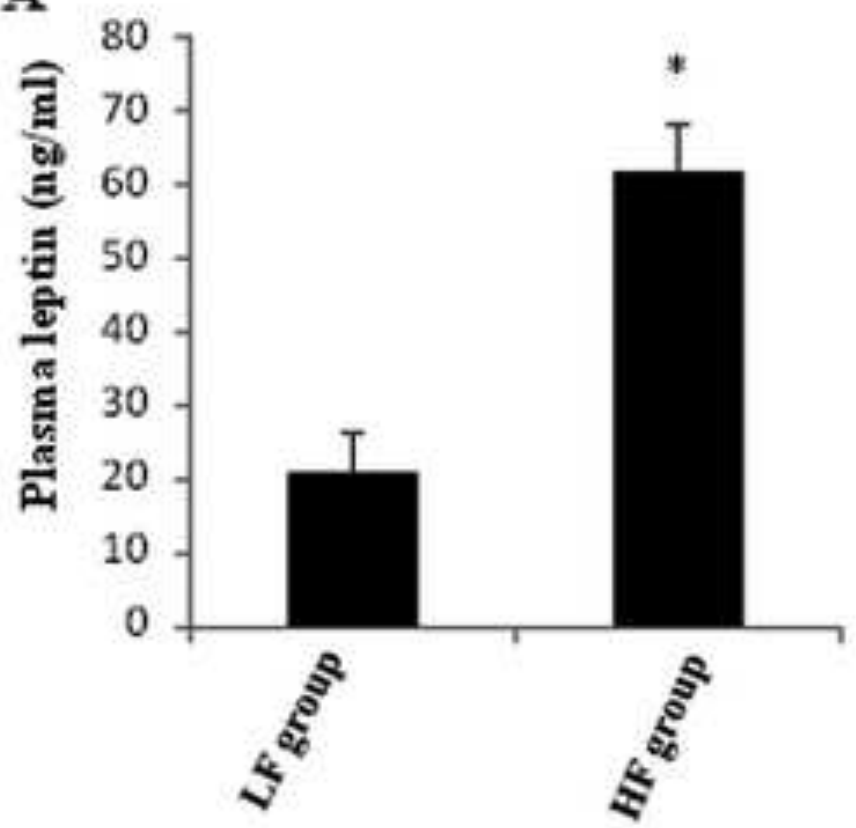

C

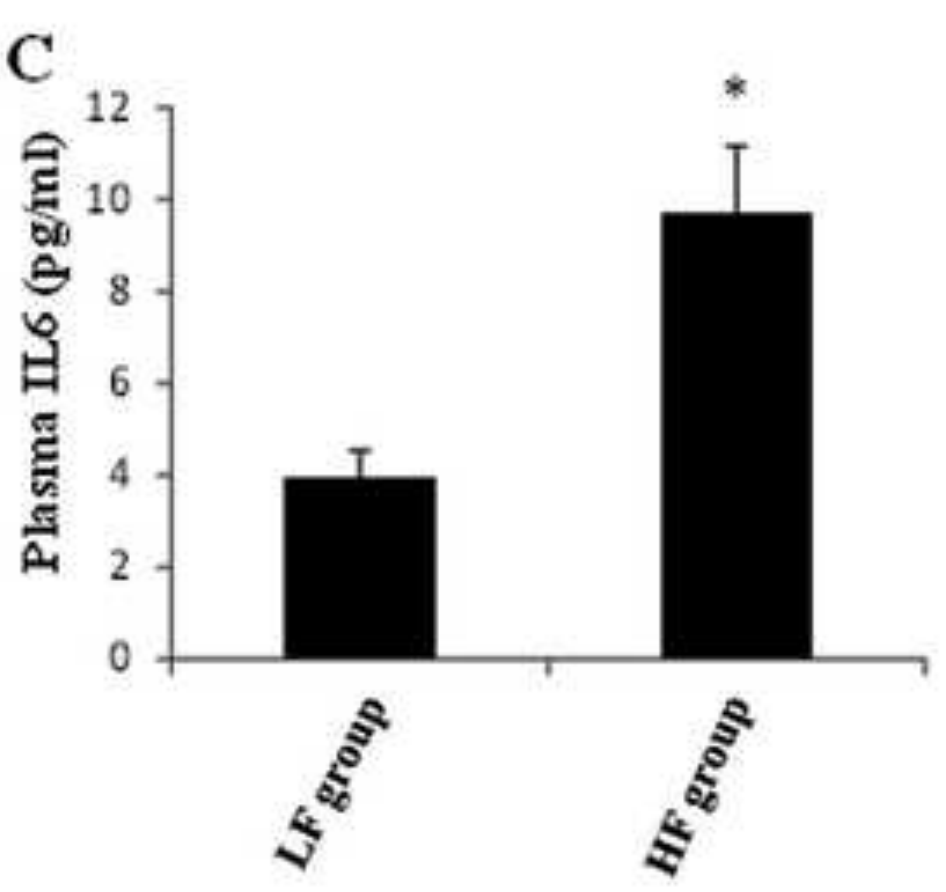

B

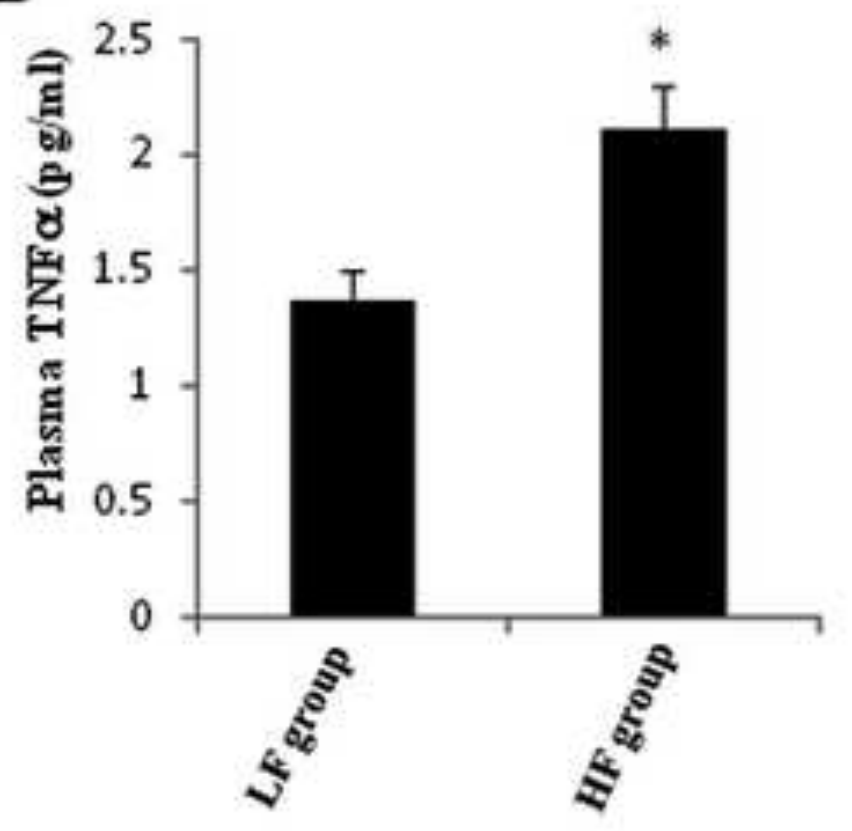

D

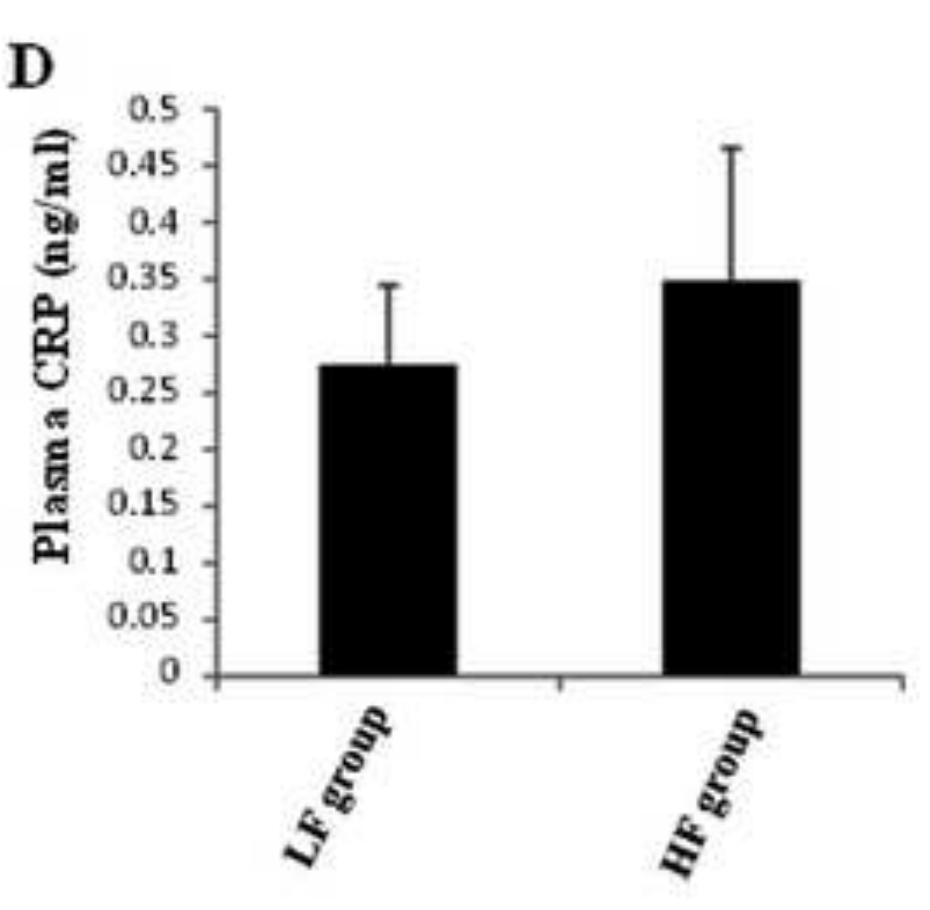


Inflammatory

cells

B

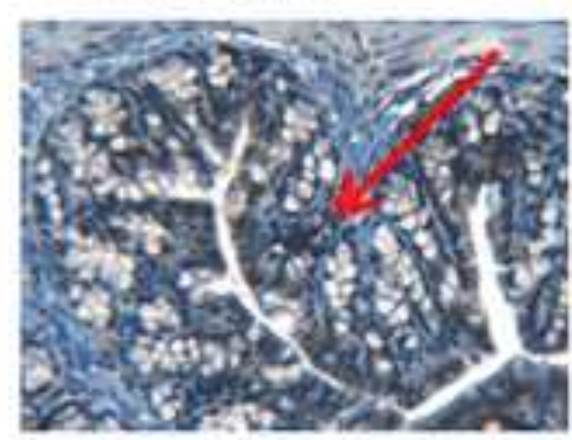

iNOS

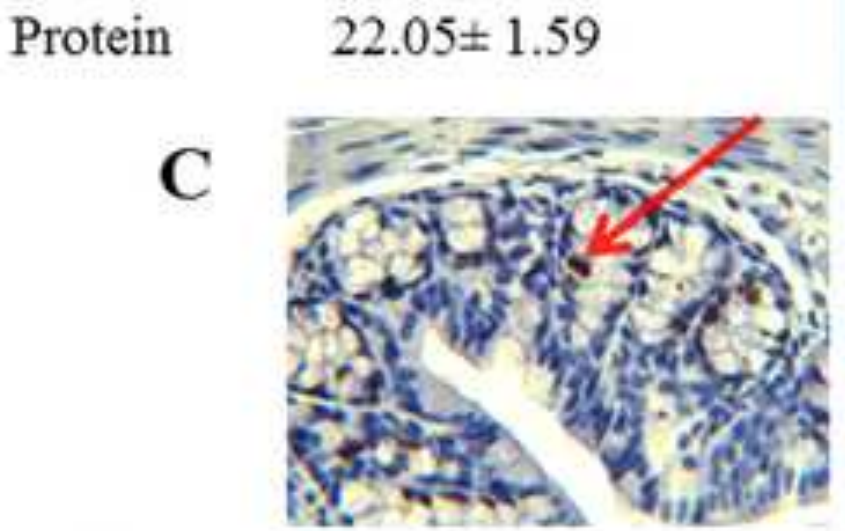

Ki67

protein

D

$\beta$-catenin

protein

$0.35 \pm 0.13$

$$
22.05 \pm 1.59
$$

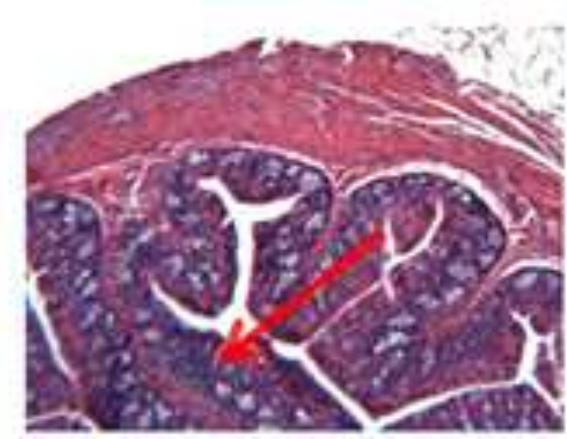

$31.73 \pm 2.15^{\text {** }}$

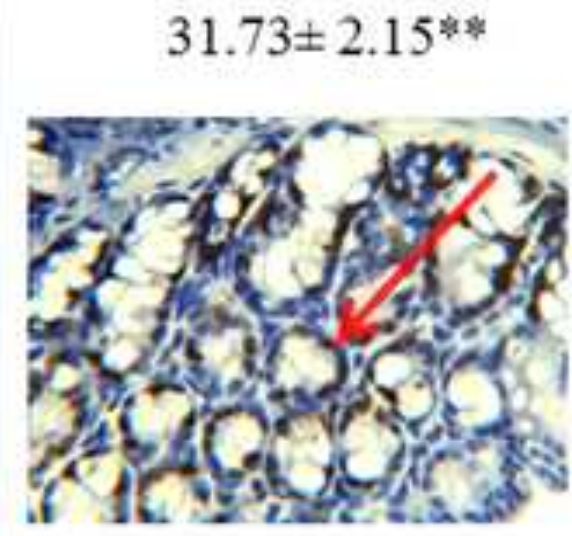

$67.72 \pm 12.99^{*}$

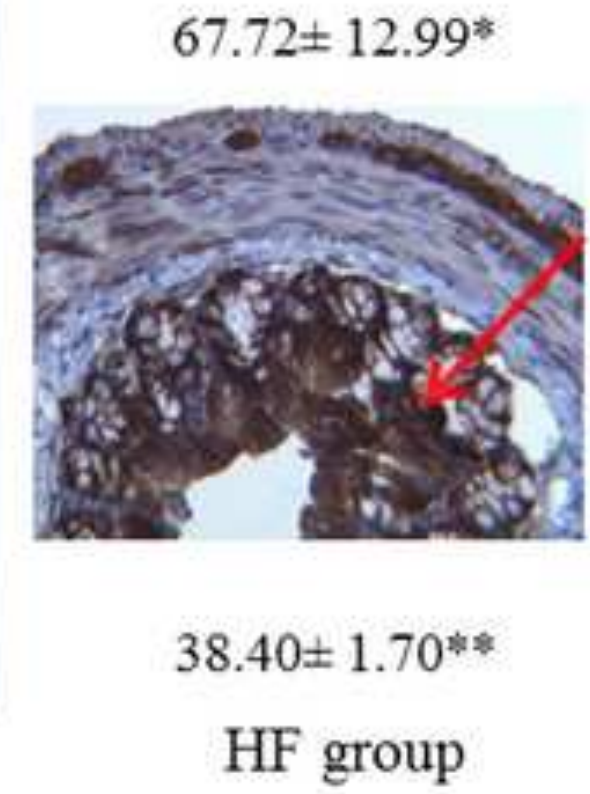

$38.40 \pm 1.70$ **

HF group

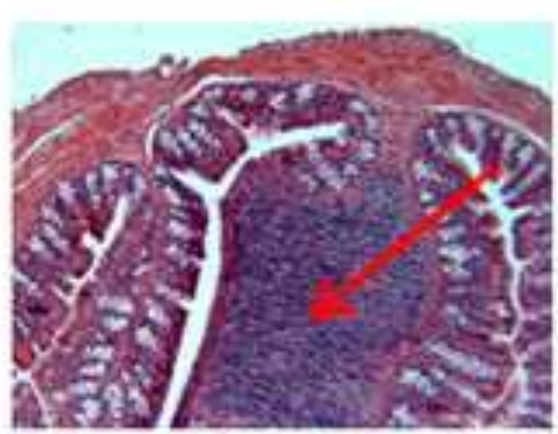

$1.23 \pm 0.22 * *$

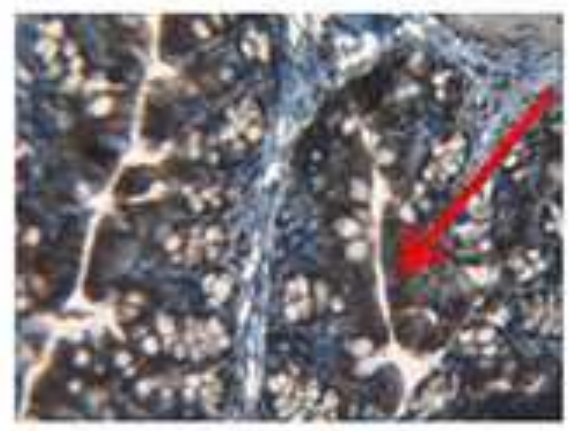


Inflammatory
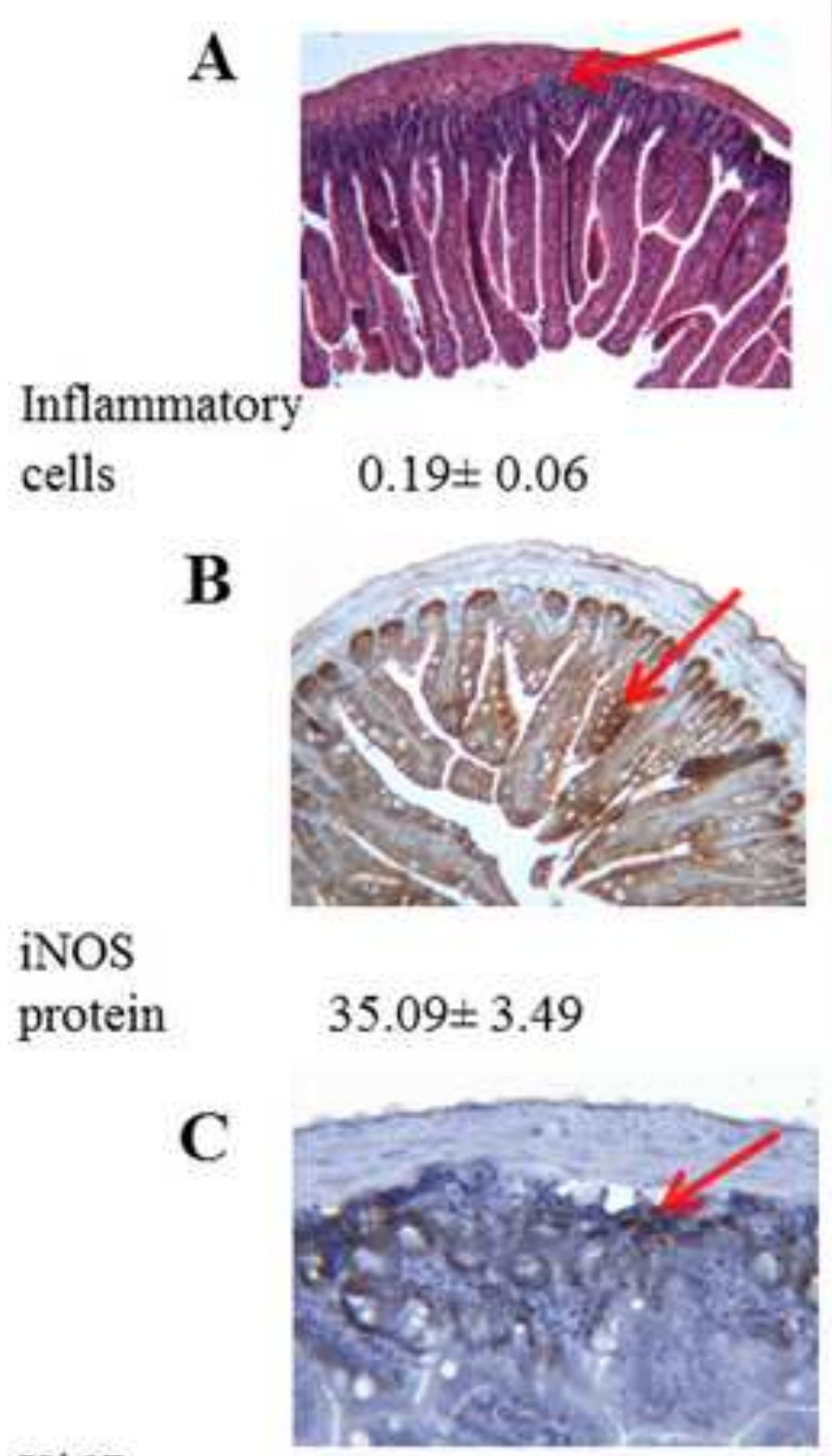

Ki67

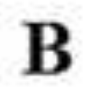

protein

D

$\beta$-catenin

protein
$9.71 \pm 1.03$

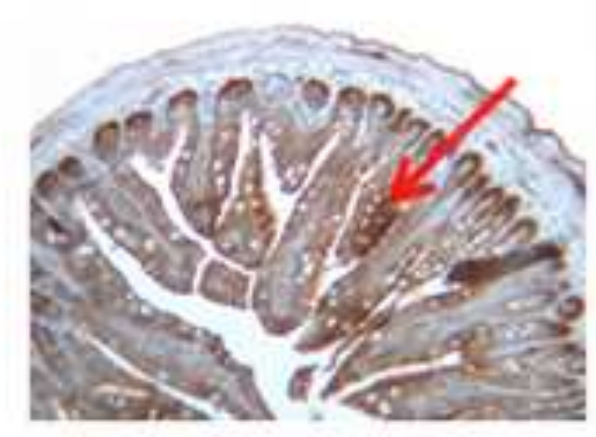

$35.09 \pm 3.49$

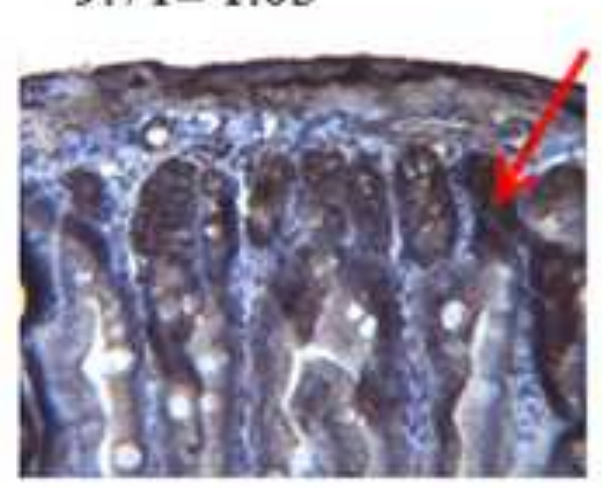

$39.03 \pm 3.34$

LF group
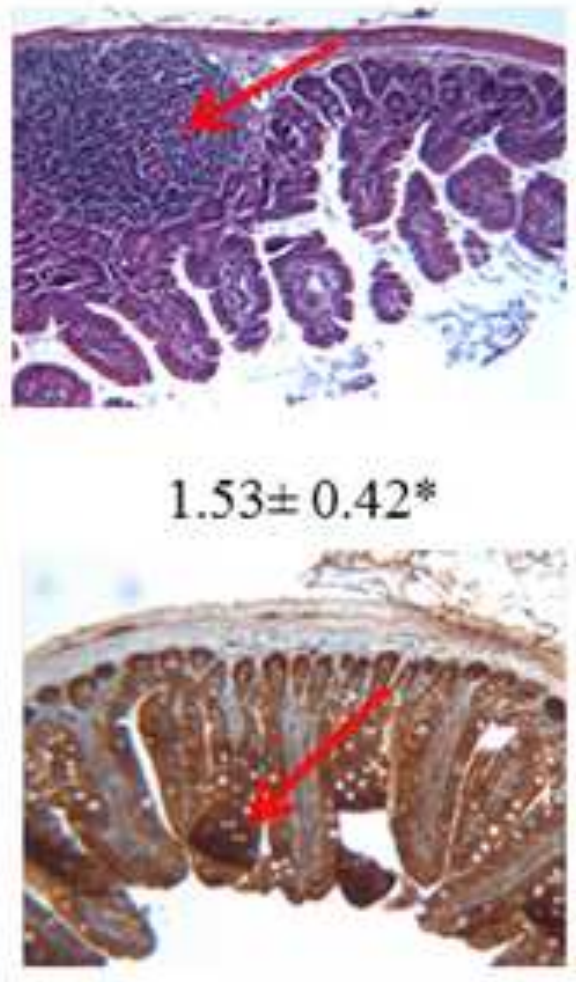

$58.15 \pm 3.68^{* *}$

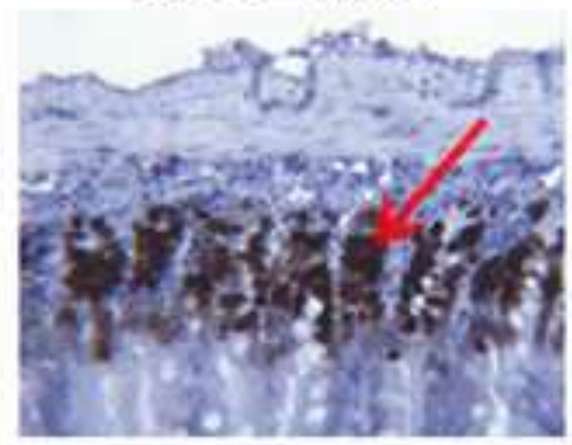

$16.71 \pm 1.94$ *

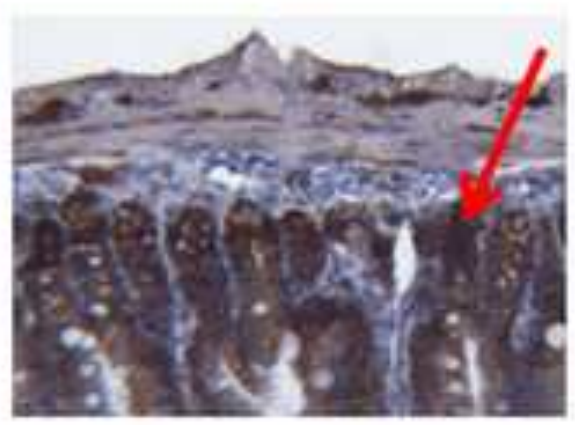

$46.50 \pm 2.05$

$\mathrm{HF}$ group 


\section{HF}

1,056 non-shared sequences

\section{LF}

569 non-shared OTUs

164 shared OTUs

703 non-shared sequences
2,181 shared sequences
809 non-shared OTUs (1)

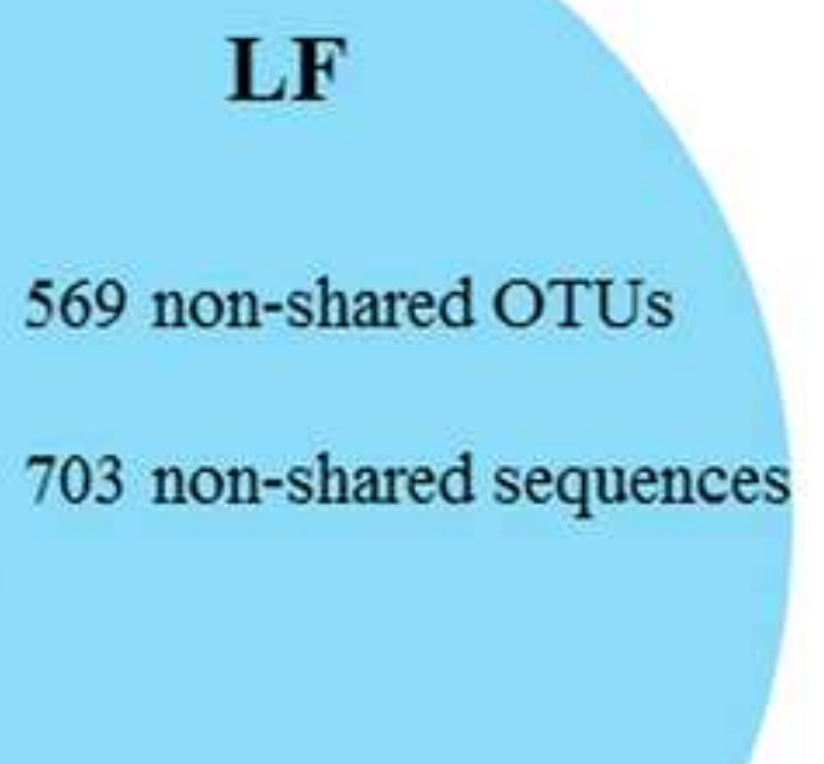


Figure 6

A
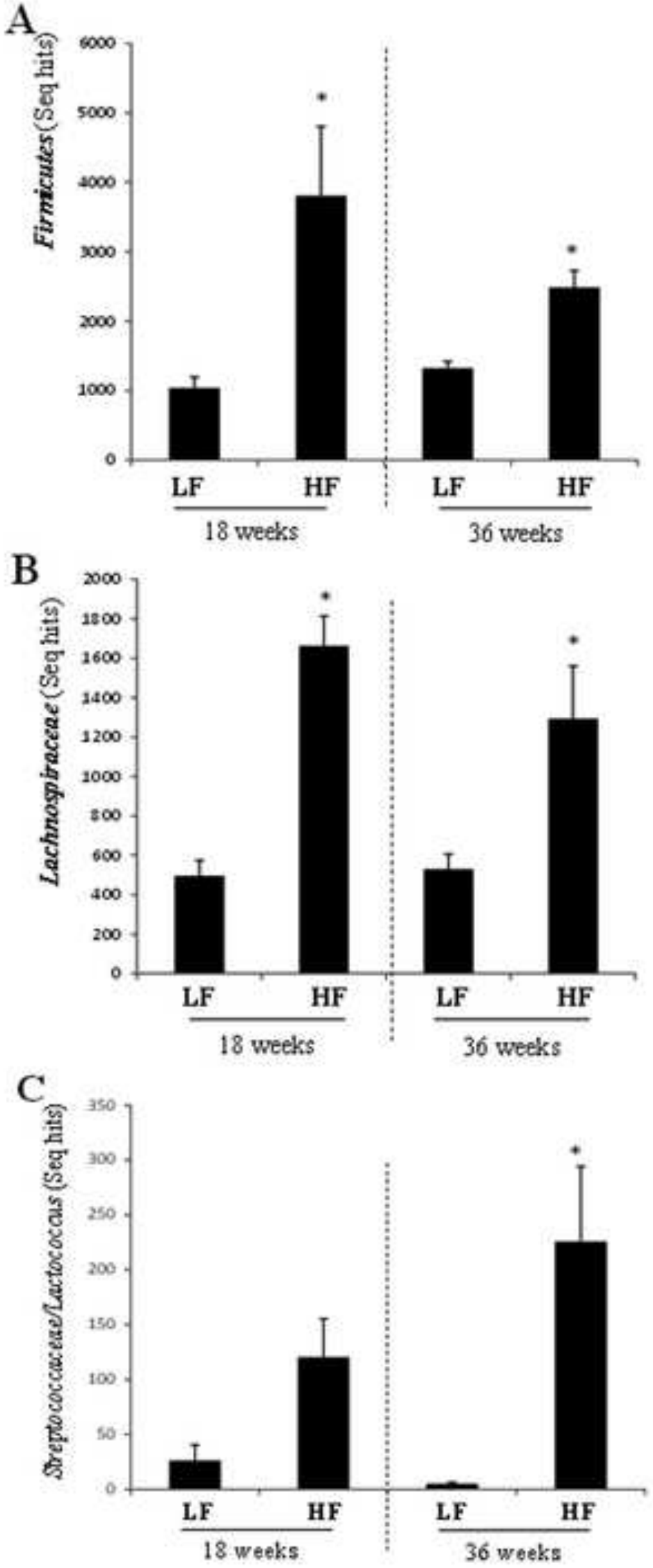